\title{
Lipid Inclusion
}

National Cancer Institute

\section{Source}

National Cancer Institute. Lipid Inclusion. NCI Thesaurus. Code C32989.

A detectable aggregation of lipids or membrane fragments in the cytoplasm. 